\title{
Investigation of the motion processes of wastewater in sewerage of high-rise buildings
}

\author{
Valentina Pomogaeva ${ }^{1, *}$ Lyudmila Metechko $^{2}$, Dmitry Prokofiev $^{2}$, and Tamara Narezhnaya ${ }^{3}$ \\ ${ }^{1}$ Voronezh State Technical University, Moscow Avenue, 14, Voronezh, 394026, Russia \\ ${ }^{2}$ Moscow Aviation Institute (National Research University), Volokolamskoe highway, 4, Moscow, \\ 125993, Russia; \\ ${ }^{3}$ Moscow State University of Civil Engineering, Yaroslavskoe sh. 26, Moscow, 129337, Russia
}

\begin{abstract}
When designing, constructing and operating sewage pipelines in high-rise buildings, issues of failure-free operation of a network arise. Investigation of the processes of wastewater moving allows identifying problem areas during operation, assessing the possibility of obstructions and breakdowns of plumbing traps on the gravity drainage sections of the pipeline. The article performs the schemes of the water outflow from the floor sewer into the riser, including the places where the riser is bent, of air delivery to the working riser under the change of the direction of drain movement with the dropout line set-up, with the installation of an automatic anti-vacuum valve, with the installation of the ventilation pipeline. Investigations of the process of sewage waste flow in a sewage riser were carried out, in order to select the appropriate structure. The authors consider structure features of some sections of sewerage in high-rise buildings. The exhaustion value in the riser is determined from the rarefactions that occur below the compressed cross-section of the riser and the loss of the air flow pressure coming from the atmosphere into the riser during the deflooding of the liquid. Preventing the formation of obstructions and breakdowns of plumbing traps is an integral part of sewage networks.
\end{abstract}

\section{Introduction}

Engineering networks ensure normal life activity of people living and working in highrise buildings. Therefore, the networks should be reliable and safe. Water supply and sewage systems are the obligatory part of each building where people reside. The discharge of wastewaters into the sewage system depends on the water consumption regime. Preventing the formation of obstructions and breakdowns of plumbing traps is an integral part of sewage networks. The present work investigates the process of flow of sewage in a sewer pipe.

The sewage riser consists of a working vertical part, an exhaust part and a horizontal pipeline transporting the waste liquid to a centralized sewerage network. The exhaust part of the sewer riser is designed for air inflow from the atmosphere, when the sewage fluid moves through the riser, for normal air exchange. At the minimal wastewater removal, the sewage gases from the sewerage network emerge from the exhaust to the atmosphere. At the

\footnotetext{
* Corresponding author: pomogaeva8@mail.ru
} 
maximum wastewater removal through the exhaust part, air is taken from the atmosphere, for normal operation not only of the sewer riser, but also of the external drainage network.

The flow of wastewater in a sewer riser is possible under different conditions: laminar, mixed or turbulent. In some parts, a water blockage can occur, covering the entire section of the pipe. In this case, a sharp pressure fluctuation arises in the riser, which can lead to a breakdown of the hydraulic shutter. The level of rarefaction will obviously depend on the speed of the falling wastewater. Since the velocity is a function that depends on the geometric length through which the volume of liquid passes during the certain time, for example, so when the liquid falls from a height of $50 \mathrm{~m}$, the speed can be $4 \mathrm{~m} / \mathrm{s}$. This can lead to the occurrence of critical-value exhaustion, leading to a breakdown of the plumbing trap. As a result of analytical calculations for sewer risers not exceeding $41 \mathrm{~m}$ in diameter $100 \mathrm{~mm}$, the throughput is $4.4-4.5 \mathrm{l} / \mathrm{s}$, for the diameter $125 \mathrm{~mm}-6-6.98 \mathrm{l} / \mathrm{s}$, for the diameter $150 \mathrm{~mm}-10$ $1 / \mathrm{s}$, and breakage of the plumbing trap is possible at a flow rate of $9 \mathrm{l} / \mathrm{s}$ for $100 \mathrm{~mm}$ and $20 \mathrm{l} / \mathrm{s}$ at $200 \mathrm{~mm}$.

\section{Materials and Methods}

When moving in a vertical sewer pipe, the sewage liquid ejects a certain volume of air (Fig. 1). The volume of air drawn into the riser first increases, then reaches a maximum value depending on the volume of water, then decreases. As a result, a water-air environment with a certain amount of sanitary waste is formed in the riser. The formation of different regimes of motion can be considered taking into account the volume gas content $\beta$ and the gas saturation of the mixture $\alpha$, which can be determined from the expressions:

$$
\beta=\frac{u_{w 0}}{u_{w 0}-u_{a 0}}=\frac{Q_{w 0}}{Q_{w 0}-Q_{a 0}} \quad \text { and } \quad \alpha=\frac{1}{\omega} \sum_{i}^{n} \omega_{w, i} .
$$

where $u_{w 0}$ - adjusted liquid phase velocity; $u_{a 0}$ - adjusted velocity of the gas phase; $Q_{0}^{\prime \prime}$ -

liquid discharge; $Q_{0}^{\prime}$ - attracted airflow rate; $\omega$ - liquid surface area; $i$ - the number of sections considered in a certain period of time.

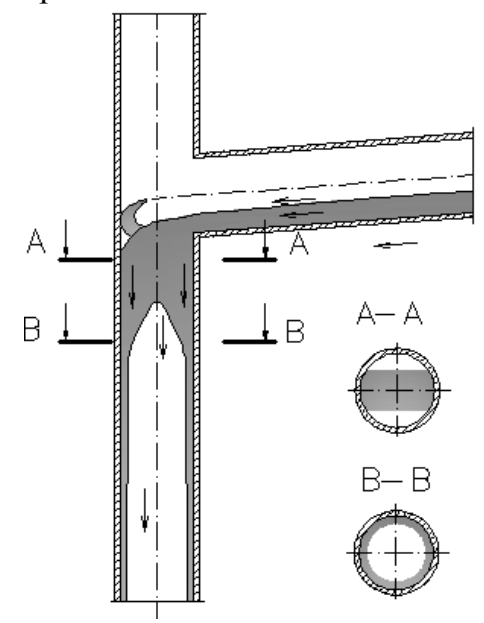

Fig. 1. Circuit of the flow of liquid from the floor sewer to the riser [1].

The differential equation for the equilibrium of forces acting in a flowing-down film has the following form:

$$
\frac{d \tau}{d X}+\gamma_{w}=0
$$


where $\tau=\mu_{w} \frac{d u_{w}}{d X}$ is viscous shear, $\mathrm{Pa} ; \gamma_{w}$ - liquid specific density, $\mathrm{N} / \mathrm{m}^{3} ; \mu_{w}$ - coefficient of dynamic viscosity of liquid, Pas; $u_{w}$ - local velocity of liquid, $\mathrm{m} / \mathrm{s}$.

To obtain the expression describing the change in the velocity of particles in the plane of the living section of the liquid film, we integrate equation (1) under the boundary conditions $X=0 \quad u_{w}=0$ and when $X=\delta_{w} \quad \tau=0$ :

$$
u_{w}=\frac{\gamma_{w}}{\mu_{w}}\left(\delta_{w} X-0,5 X^{2}\right)
$$

where $\delta_{w}$ - boundary layer thickness, $\mathrm{m}$.

When $X=\delta_{w}$, the velocity on the outer surface of the film reaches a maximum value $u_{\text {w.max }}=\frac{\gamma_{w}}{2 \mu_{w}} \delta_{w}^{2}$, while the average velocity of the fluid in the wetted section of the film is equal to: $u_{w . c p}=\frac{1}{\delta_{w}} \int_{0}^{\delta_{w}} u_{w} d X$.

Taking into account equation (2), the average velocity will be:

$$
u_{w . c p}=\frac{\gamma_{w}}{3 \mu_{w}} \delta_{w}^{2},
$$

The volume flow of liquid in the film flowing down the inner surface of the pipe is determined by the equation:

$$
Q_{w}=\pi D \delta_{w} u_{w . c p}=\pi D \frac{\gamma_{w}}{3 \mu_{w}} \delta_{w}^{3},
$$

where $D$ is the diameter of the pipe, $\mathrm{m}$.

From equation (4), the thickness of the flowing fluid film is determined:

$$
\delta_{w}=\sqrt[3]{3 \frac{Q_{w} \mu_{w}}{\pi D \gamma_{w}} .}
$$

From (3) and (5) the average velocity in the wetted section of the liquid film is:

$$
u_{w . c p}=\sqrt[3]{\frac{1}{3}\left(\frac{Q_{w}}{\pi D}\right)^{2} \frac{\gamma_{w}}{\mu_{w}}},
$$

The velocity of the gas layer at the outer boundary of the flowing liquid film in the velocity of its wetted section is not the same and is subjected to a complex dependence. At the interface between the liquid and the gas, the velocity of the fluid is equal to the velocity of the water. In the first approximation, the velocity of the gas can be assumed to change linearly; hence, the magnitude of the viscous shears is constant across the width of the layer. In this case, the equation of equilibrium of the forces acting in the gas layer has the form:

$$
\mu_{a} \frac{d^{2} u_{a}}{d \delta_{a . n}^{2}}=0,
$$

where $\mu_{a}$ - coefficient of dynamic viscosity of air, Pa.s; $u_{a}$ - local velocity in the gas layer, $\mathrm{m} / \mathrm{s} ; \delta_{a . n}$ - the distance along the normal line from the surface of the film in the cross section of the wetted section of the gas layer, $m$

The local velocity in the gas layer is determined from equation: $u_{a}=u_{w, \max }\left(1-\delta_{a, n} / \delta_{a}\right)$, where $\delta_{a}$ - thickness of the gas layer, $\mathrm{m}$. 
The average velocity of motion in the plane of the live section of the gas layer, under boundary conditions $\delta_{a . n}=0 \quad u_{a}=u_{w, \max }$ и $\delta_{a . n}=\delta_{a} \quad u_{a}=0$ equals:

$$
u_{a, c p}=\frac{1}{\delta_{a}} \int_{0}^{\delta_{a}} u_{a} d \delta_{a . n}=\frac{u_{w, \max }}{2} .
$$

Hence, the average velocity of motion in the plane of the wetted section of the gas layer is a function of the maximum fluid velocity.

The volume flow of air entering the riser can be determined as follows:

$$
Q_{a}=\pi D_{a}^{\prime} \delta_{a} u_{a, c p}
$$

where $D_{a}^{\prime}$ - The diameter of the gas layer along the upper surface of the liquid film.

The thickness of the gas layer can be assumed according to the distance from the outer boundary of the liquid film, at which its velocity is maximum, that is:

$$
\delta_{a}=5 \sqrt{\frac{L v_{a}}{u_{w, \max }}} .
$$

where $v_{a}$ - kinematic viscosity of air, $\mathrm{m}^{2} / \mathrm{s} ; 5$ - the Blasius coefficient.

The surface of the liquid film of the wastewater carries the air. To determine its volumetric flow, equalities (3), (6), (8), (10) are used. Taking into account that the thickness of the liquid film is much smaller than the diameter of the tube, the volume flow of air can be assumed equaling to:

$$
Q_{a}=2,5 \pi D \sqrt{L v_{a}} \sqrt[3]{\frac{Q_{w}}{\pi D}} \sqrt[6]{\frac{\gamma_{w}}{\mu_{w}}} .
$$

By formula (11), it is possible to determine theoretically the ejecting capacity of a liquid when local resistances are absent.

There are local in the sewage system. For example, when wastewater leaves the floor sewer, a local hydraulic resistance arises in the riser in the form of a water-air mass acting as some kind of a piston. Consequently, there is some air deficit below the section pressed by a "piston" (Fig. 1.). In this case, the formula obtained from the Bernoulli equation can be used to determine the air flow;

$$
Q_{a}=\mu \omega_{a} \sqrt{\frac{2 g}{\gamma_{a}} \Delta p},
$$

where $\mu$ - discharge coefficient; $\omega_{a}$ - area of the wetted section of air in the compressed section of the riser, $\mathrm{m}^{2} ; \gamma_{a}$ - specific gravity of air, $\mathrm{kg} / \mathrm{m}^{3} ; \Delta p$ - pressure difference $(\mathrm{Pa}) ; \mathrm{g}-$ gravitational acceleration $\mathrm{m} / \mathrm{s}^{2}$.

To determine the pressure difference or the exhaustion in the sewage riser, equations (11), (12) are solved relatively to the pressure difference $\Delta p$ :

$$
\Delta p=\frac{\left(2,5 \pi D \sqrt{L v_{a}} \sqrt[3]{\frac{Q_{w}}{\pi D}} \sqrt[6]{\frac{\gamma_{w}}{\mu_{w}}}\right)^{2} \gamma_{a}}{2 g \mu^{2} \omega_{a}^{2}}=\frac{1}{\mu^{2}} \frac{Q_{a}^{2}}{2 g \omega_{a}^{2}} \gamma_{a}=\xi \frac{v^{2}}{2 g} \gamma_{a}
$$

where $\xi$ - local resistance coefficient; $v$ - air velocity in the compressed section of the riser, $\mathrm{m} / \mathrm{s}$. 


\section{Results}

Therefore, by analyzing the expression (13), it is possible to determine the exhaustion volume in the riser and the effect of the main parameters of liquid and air motion. The exhaustion volume will increase with an increase in the flow rate of the waste liquid. As the volume of the liquid increases, its ejecting capacity increases, and the area of the wetted section of air in the compressed section of the riser will decrease. For example, if the area of the wetted section of the air is doubled, then by (13) the pressure drop is reduced by a factor of four. Accordingly, it is necessary to increase the cross-sectional area of air in the compressed cross-section of the riser when the condition of the fluid inlet into the riser, for example, the angle of attachment of the sub-assemblies or the reduction in their diameter, changes. If we consider the option of reducing the diameter of the venting part of the riser, for example, during freezing in the winter period, then the magnitude of the discharge in the riser will tend to infinity at the area of the live cross section of air in the compressed cross section of the riser tending to zero. In this case, increasing the diameter of the venting part of the riser in comparison with the diameter of its working part is ineffective, since the airflow depends on the working diameter of the riser.

Analyzing expression (13), several conclusions can be made:

1. The exhaustion (vacuum-gauge pressure) will reach a maximum value "at the end of the length of the initial section L. Further increase in the height of the riser does not affect the volume of the exhaustion [2]".

2. The change in air parameters slightly affect the amount of exhaustions in the sewer riser and can be neglected in calculation, since the specific gravity of the air $\gamma_{a}$ and the kinematic viscosity $v_{a}$ placed in the numerator change proportionally.

3. As the roughness of the pipeline material increases, the length of the initial section decreases, and the volume of exhaustions arising in the riser decreases.

The use of expression (13) in practical calculations is very difficult, since it is practically impossible to determine the exact values of the area of the wetted section of air $\omega_{a}$ in the compressed cross section of the riser, as well as and the flow coefficient $\mu$.

Experiments conducted by A.Y. Dobromyslov [3] on sewerage systems of different diameters, heights, attachment angles, and the heights of the hydraulic seal, have shown the necessity of determining $\Delta p$. It was found that "the amount of ejection capacity increases only in the riser section equal to 90 diameters from the point of entry of liquid into it. With an increase in the working height of the riser ... the air flow rate does not change [2] ". As a result of experimental studies [1], a formula was obtained for determining the amount of exhaustions in the riser (14), which is used for practical calculations in the design of the sewage systems in Russia [6]:

$$
\Delta p=\frac{366\left(\frac{Q_{w}}{(1+\cos \alpha) D^{2}}\right)^{1,677}}{\left(\frac{D}{d}\right)^{0,71}\left(\frac{90 D}{L}\right)^{0,5}},
$$

where $\Delta p$ - volume of exhaustions in the riser, mm w.g.; $Q_{w}-$ design flow rate of wastewater, $\mathrm{m}^{3} / \mathrm{s} ; \alpha$ - angle of junction of the floor sewer to the riser, degr; $D$ - design (internal) diameter of the riser, $\mathrm{m} ; d$ - design (internal) diameter of the floor sewer, $\mathrm{m} ; L$ working height of the sewer riser.

Y. Dobromyslov theoretically established and experimentally confirmed that "the air flow rate coming above its compressed section is affected not by the entire height of the riser, but only by the length of its initial section equal to 90D" [4]. Thus, formula (14) will be 
considerably simplified when calculating the sewerage system of high-rise buildings, in which the height of the working riser is much larger than its diameter. For risers of big height, the multiplier $\sqrt{90 D / L}$ is not taken into account, so the formula takes the form of

$$
\Delta p=\frac{366\left(\frac{Q_{w}}{(1+\cos \alpha) D^{2}}\right)^{1,677}}{\left(\frac{D}{d}\right)^{0,71}} .
$$

When $L>>90 D, \alpha=90^{\circ}, D=d \Delta p=366\left(\frac{Q_{w}}{D^{2}}\right)^{1,677}$.

Calculations in the design of sewage systems of buildings of various purposes, including high-rise ones are made using the formula (14). When calculating by this formula, the critical fluid flow rates $\mathrm{Q}_{\mathrm{w}, \mathrm{cr}}$ are determined. When critical fluid flow rate exceeds, the plumbing trap can be detached. For example, with a $70 \mathrm{~mm}$ high plumbing trap, the critical flow rate is:

- at $\mathrm{D}=100 \mathrm{~mm}, \mathrm{~d}=100 \mathrm{~mm}$ and $\alpha=45^{\circ} Q_{w, c r}=7.32 \mathrm{l} / \mathrm{s}$, and at $\alpha=90^{\circ} Q_{w, c r}=4.2 \mathrm{l} / \mathrm{s}$;

- at D $=125 \mathrm{~mm}, \mathrm{~d}=100 \mathrm{~mm}$ and $\alpha=45^{\circ} Q_{w, c r}=12.5 \mathrm{l} / \mathrm{s}$, and at $\alpha=90^{\circ} Q_{w, c r}=4.3 \mathrm{l} / \mathrm{s}$;

- at $\mathrm{D}=150 \mathrm{~mm}, \mathrm{~d}=100 \mathrm{~mm}$ and $\alpha=45^{\circ} Q_{w, c r}=19.3 \mathrm{l} / \mathrm{s}$, and at $\alpha=90^{\circ} Q_{w, c r}=11.34 \mathrm{l} / \mathrm{s}$.

If the height of the hydraulic shutter is $60 \mathrm{~mm}$, the critical flow rate will be:

- at $\mathrm{D}=100 \mathrm{~mm}, \mathrm{~d}=100 \mathrm{~mm}$ and $\alpha=45^{\circ} Q_{w, c r}=6.1 \mathrm{l} / \mathrm{s}$, and at $\alpha=90^{\circ} Q_{w, c r}=3.54 \mathrm{l} / \mathrm{s}$;

- at D $=125 \mathrm{~mm}, \mathrm{~d}=100 \mathrm{~mm}$ and $\alpha=45^{\circ} Q_{w, c r}=10.4 \mathrm{l} / \mathrm{s}$, and at $\alpha=90^{\circ} Q_{w, c r}=6.12 \mathrm{l} / \mathrm{s}$;

- at $\mathrm{D}=150 \mathrm{~mm}, \mathrm{~d}=100 \mathrm{~mm}$ and $\alpha=45^{\circ} Q_{w, c r}=16.1 \mathrm{l} / \mathrm{s}$, and at $\alpha=90^{\circ} Q_{w, c r}=9.45 \mathrm{l} / \mathrm{s}$.

If the height of the hydraulic shutter is $50 \mathrm{~mm}$, the critical flow rate will be:

- at D $=100 \mathrm{~mm}, \mathrm{~d}=100 \mathrm{~mm}$ and $\alpha=45^{\circ} Q_{w, c r}=4.9 \mathrm{l} / \mathrm{s}$, and at $\alpha=90^{\circ} Q_{w, c r}=2.8 \mathrm{l} / \mathrm{s}$;

- at $\mathrm{D}=125 \mathrm{~mm}, \mathrm{~d}=100 \mathrm{~mm}$ and $\alpha=45^{\circ} Q_{w, c r}=8.32 \mathrm{l} / \mathrm{s}$, and at $\alpha=90^{\circ} Q_{w, c r}=4.9 \mathrm{l} / \mathrm{s}$;

- at $\mathrm{D}=150 \mathrm{~mm}, \mathrm{~d}=100 \mathrm{~mm}$ and $\alpha=45^{\circ} Q_{w, c r}=12.88 \mathrm{l} / \mathrm{s}$, and at $\alpha=90^{\circ} Q_{w, c r}=7.56 \mathrm{l} / \mathrm{s}$.

From critical flow rates above, one can see that the higher the hydraulic shutter is, the greater the flow can pass the sewer riser and the system will operate without disruption. It has been experimentally established that the hydraulic shutter failure occurs when the air pressure in the riser becomes less than atmospheric pressure by an amount equal to or slightly higher than the height of the hydraulic shutter. The rarefaction in the riser arises from the discrepancy between the amount of the ejecting capacity of the liquid (ie, the ability of water moving down the riser to entrain air) and the value of the actual airflow entering the riser through its exhaust.

\section{Discussions}

Under conditions of modern construction, little attention is paid to the height of plumbing traps. This is particularly evident in the free planning of apartments, when the owners of the apartments have the opportunity to install sanitary equipment themselves. However, the minimum height of the hydraulic shutter of $50 \mathrm{~mm}$ will always be respected due to the design of the plumbing traps and the height of installation of sanitary devices.

In modern design of high-rise buildings, rooms of uninhabited purpose are located on floors 1-3 and the location of sanitary equipment of those floors do not coincide with the placement of sanitary conveniences of residential floors. When the location of equipment and sewage compositions of different floors are strongly differ, it is advisable to use a separate sewage system, for example using automatic vacuum valves to supply air to the lower part of the sewerage of a high-rise building. Connecting the venting part of the riser to the working riser or to a separately venting riser creates additional costs. One of the options 
is to unite the sewer risers from the residential part of the building and other premises, with the arrangement of indentations or overruns. In this case, it is necessary to ensure the same air pressure in the riser sections as it moves to the horizontal direction, particularly at two inflection points (point 1, 2, Fig. 2). Consider the motion of the wastewater when creating an offset.

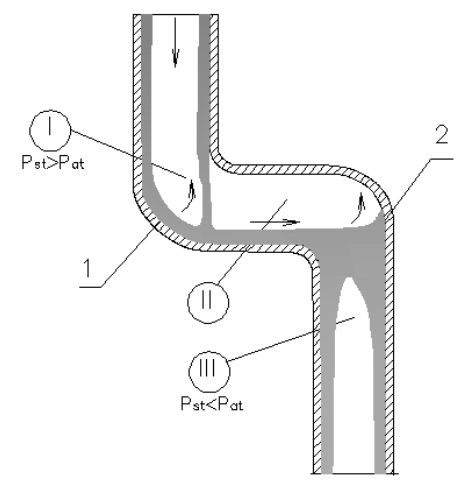

Fig. 2. Change of flow regimes of liquid and air [5]: 1,2 - inflection points of the riser.

Since the liquid moves down the walls of the pipe in a vertical riser under the gravity, it falls in the first zone and overlap of the cross-section of the pipe surface of the horizontal section occurs (zone I, Fig. 2). As a result, a local resistance is created from the liquid film, which prevents the flow of air. The drop in the air flow rate will lead to an increase in the pressure in the sewer stand at the bend point (poit 1, Fig. 2). There are options for the appearance of a pressure that is much greater than the atmospheric pressure, in this case, if a sanitary and technical device falls into such a region, under the influence of excessive pressure, it can spill out sewage and sewage gases from the hydraulic shutter into the bowl of the device. When the pressure in the riser is stabilized, the water will fill the hydraulic shutter.

With further movement, the liquid enters the horizontal section, where the "separated" motion of the liquid and air occurs (zone II, Fig. 2). Sewage flows along the bottom of the pipe without obstructions, air moves above it. The steady-state fluid-air flow regime changes dramatically at the second inflection point (point 2, Fig. 2). Here the liquid fills the vertical section of the riser, a compressed section is formed, which prevents the movement of air. Thus, a part of the sewer riser located below the offset is cut off from normal atmospheric pressure in the following sections:

Fig. 1);

- at the point where the liquid enters the riser from the floor tap (cross-section A-A,

- at the first point of inflection of the riser (point 1, zone I, Fig.2), there is a dramatic increase of the air pressure in the riser;

- under the second inflection point of the riser (point 2, zone III, Fig.2), there is a dramatic increase in the air deficit.

In this case, if the sanitary-technical device is located under the second inflection point, it is possible to break the plumbing trap of the device, since the lower part of the riser becomes unventilated at some point in time. This option is possible on the lower floors of the building. To prevent such phenomena, it is advisable to smoothly switch from a vertical section to a horizontal section of a sewer pipe using $45^{\circ}, 30^{\circ}$ or $22.5^{\circ}$ bridles. Another option to prevent the shut-off of the plumbing trap is the installation of a bypass line (piping in the form of a loop) connecting riser sections with increased and reduced pressure (Fig. 3a) or riser equipment located below the second inflection point by a vent valve (Fig.3b, 3c) [5] . 

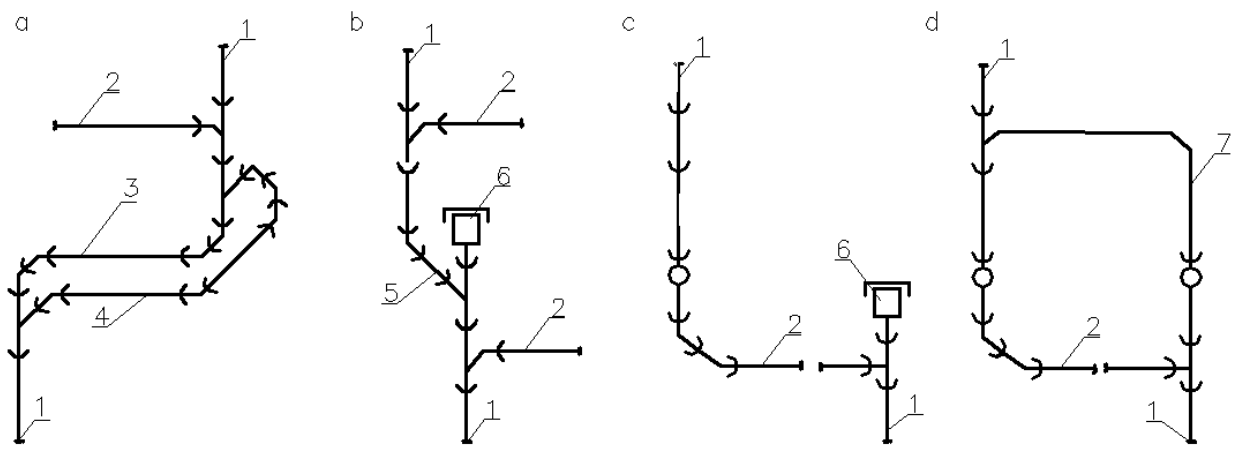

Fig. 3. Circuit of air supply to the working riser with a change in the flow direction

a) with the device of a branch line (loop-like pipeline),

b), c) with the installation of an automatic anti-vacuum valve

d) with the installation of a ventilation pipeline (bypass);

1-sewer riser; 2-floor sewer; 3 - offset; 4 - branch line; 5- overturn;

6 - automatic anti-vacuum valve; 7 - - vent line (bypass)

In the premises of various purposes located on the 1-3 floors of high-rise buildings, a large number of devices can be installed on one horizontal arrangement of the sewage system. If the sanitary devices are removed far from the riser, it is advisable to install an antivacuum valve (Fig.3c) or a vent line (Fig. 3d) to prevent self-siphoning of the plumbing traps. The anti-vacuum valve is installed near the far device counting from the working riser (pos. 6, Fig. 3c). The ventilation pipeline also connects the sanitary equipment with the ventilation riser, connected to the horizontal pipeline and the working riser (pos.7, Fig. 3d), which is far from the working riser. Particular attention is paid to the condition that "the product of the slope of the horizontal pipeline exceeds its length by the height of the hydraulic shutter of a specific sanitary and technical device "[5].

"As the number of fixtures increases, venting needs to do as well, evolving into a venting system, with branch, circuit, and loop at the appropriate locations" [6]. In the Russian construction practice, a two-pipe system is rarely used, in contrast to the foreign experience. This is due to the increase in the cost of such a system. The diameters and design of the system are calculated in such a way that they allow the maximum possible trouble-free operation. Theoretical studies also show that the ejected air is sufficient, with one sewer riser with an exhaust port.

Thus, the article justifies the use of various design features of sewage systems in highrise buildings, taking into account trouble-free operation in terms of plumbing traps. However, one of the significant hazards in the sewage system is the possibility of obstructions. As a result, the first floors can be flooded, since the design flow rate of effluents can reach 4-6 1/s. To prevent the flow of wastewater out of sanitary facilities, the water supply of a certain zone is turned off.

The presence of audit and cleaning device is a prerequisite for trouble-free operation of sewer risers. However, the authors assume that one of the main aspects is a smooth connection of a vertical riser to a horizontal section and the reduction in a number of offsets.

\section{Conclusion}

The reliability of the sewage system of high-rise buildings depends on the stability against the failure of plumbing traps and on prevention of obstructions in the gravity drainage sections of the pipeline. 
The plumbing trap failure occurs when the amount of exhaustions arising during the movement of the wastewater in the riser is greater than the height of the plumbing trap. Verification calculations are performed using formula (14).

The amount of exhaustions in the riser is made up of the exhaustions that occur below the compressed cross-section of the riser and the loss of the pressure of the airflow coming from the atmosphere into the riser when the fluid flows downward.

For trouble-free operation of sewerage in high-rise buildings, the risers should be vertical without offsets.

In some cases, the two-pipe system of sewerage is not as effective as the one-pipe system, but it is considerably inferior in simplicity and cost. In each particular case, the twopipe system of sewerage of a high-rise building should be justified by calculation.

\section{References}

1. V.P. Kamskov, I.V. Balandina, D.Y. Zemlyanushnov, Sovremennye tendentsii razvitiya nauki i tekhnologiy, 9-3, 95-99 (2015)

2. A.S. Inosemtsev, E.V. Korolev, Stroitelnye materialy, 1-2, 38-47 (2016)

3. A.N. Grishina, E.V. Korolev, Vestnik MGSU, 11, 58-67 (2016)

4. A.A. Pakhratdinov, D.V. Oreshkin, Ekologiya urbanizirovannykh territoriy, 3, 84-88 (2016)

5. A. Y. Dobromyslov, Raschet $i$ konstruirovanie sistem kanalizacii zdanij (Strojizdat, Moscow, 2012)

6. D. Connelly, CPD, 27 (2007) 